\title{
MODA, MÍDIA E VELHICE: considerações a partir do documentário Advanced Style
}

Annamaria Jatobá Palacios

Doutora, Universidade Federal da Bahia /annajatobapalacios@gmail.com

Orcid: 0000-0002-9065-0482/http://lattes.cnpq.br/02234972644558569

Larissa Molina

Mestre, Universidade Federal da Bahia /larimolina@gmail.com

Orcid: 0000-0003-1879-0840/http://lattes.cnpq.br/0223497264458569

Enviado 14/03/18 / Aceito 29/08/18 


\title{
MODA, MÍDIA E VELHICE: considerações a partir do documentário Advanced Style
}

\begin{abstract}
RESUMO
$\mathrm{O}$ artigo discute as relações entre moda, mídia e velhice a partir de uma análise do documentário Advanced Style. Verifica as representações do estilo de vida que um grupo de mulheres idosas, que se interessa por moda, estabelece com o envelhecimento, consumo e o próprio corpo. As temáticas em causa no documentário estão associadas ao contexto cultural de uma sociedade marcada pela busca por prazer e felicidade, mas também por incertezas e medos. O Mal-Estar na Civilização e na Pós-Modernidade é uma noção central no texto e concorre para explicar o medo da morte diante da finitude da vida. Outros referenciais sobre a velhice adotados no texto colaboram para explicar e evidenciar a existência de que novas interpretações de velhice vêm se desenvolvendo na contemporaneidade. As relações entre consumo, mídia, moda e estilo de vida fazem parte dos aspectos evidenciados no texto.
\end{abstract}

Palavras-chave: Velhice; Moda e Estilo; Cultura de consumo. 


\title{
FASHION, MEDIA AND OLD AGE: considerations based on the documentary Advanced Style
}

\begin{abstract}
The article discusses the relations between fashion, media and old age, based on an analysis of the documentary Advanced Style. It identifies the representations of the lifestyle that a group of elderly women, with an interest in fashion, establish with aging, consumption and their own body. The themes in the documentary are associated with the cultural context of a society marked by the search for pleasure and happiness, but also by uncertainties and fears. Malaise in Civilization (Freud) and its echoes in PostModernity is a central notion in the text and is used to explain the fear of death in the face of the finitude of life. Other notions concerning old age adopted in the text collaborate to explain and put in evidence the existence of new interpretations of old age that have been developing in contemporary society. Relations between consumption, media, fashion and lifestyle are part of the aspects highlighted in the text.
\end{abstract}

Keywords: Old Age; Fashion and Style; Consumer Culture. 


\section{INTRODUÇÃO}

O envelhecimento, associado a um processo contínuo de perdas, crescente dependência, limitação de papeis sociais e à decadência do corpo, tem sido midiaticamente contraposto a termos mais positivos, tais como, "terceira idade", "maioridade" ou até "melhor idade". No entanto, nas dimensões da moda, os padrões estéticos socialmente instituídos, e ainda hegemônicos, elegem o corpo jovem como ideal de beleza. Portanto, não se faz excessivo afirmar que as atuais interpretações acerca do envelhecimento colidem com estes padrões ainda dominantes, no contexto sócio cultural.

O presente artigo visa discutir as relações entre cultura, envelhecimento, moda e estilo, a partir de um estudo de caso sobre o documentário Advanced Style, baseado no blog, de mesmo nome, do fotógrafo Ari Seth Cohen. A tradução literal da expressão Advanced Style, na língua portuguesa, quer dizer Estilo Avançado. O documentário foi lançado em 2014 e mostra o dia a dia de sete mulheres idosas, com idades entre 62 e 96 anos que vivem na cidade de Nova York. As mulheres possuem em comum o interesse por moda. No documentário, este fato vem a contrariar algumas ideias convencionais sobre como as mulheres, usualmente, se vestem e se comportam na velhice, ao mesmo tempo em que também coloca em questão padrões de beleza vigentes, essencialmente associados à juventude.

A análise, a partir de uma breve utilização do método de Estudo de Caso possibilita, conforme Gil (1994, p, 78), um "estudo profundo e exaustivo de um ou poucos objetos, de maneira a permitir conhecimento amplo e detalhado do mesmo". Procura verificar as representações do estilo de vida que essas mulheres idosas estabelecem com a moda, o envelhecimento e o próprio corpo, destacando como esses aspectos estão associados a um contexto de inseguranças, 
ansiedades, medo, ao mesmo tempo em que também enfatiza os processos de busca por prazer, felicidade e liberdade, como ideais presentes na condição existencial humana, em qualquer idade. O estudo orienta-se pelo caráter interdisciplinar na abordagem dos temas.

Vale ressaltar que um importante referencial teórico neste texto, diz respeito à noção de Mal-estar na civilização caracterizada por Freud $([1930], 1996)$, revista por Marcuse ([1955]1975) e, mais recentemente, retomada por Bauman (1998), na chamada Pós-Modernidade. Desde Freud ([1930],1996), o Mal-Estar é caracterizado como um fenômeno civilizacional (cultural) e descrito, substancialmente, como um processo de repressão da vida instintiva. O processo de reprimir os instintos e a espontaneidade vem a gerar o que Freud ([1930], 1996) caracteriza como frustração. Não somente Freud ([1930],1996), como também Marcuse ([1955]1975) e Bauman (1998), em uma linha cronológica de análise do fenômeno, deram atenção a aspectos decorrentes dos processos de inserção e de interação social vividos pelo indivíduo com seu meio físico, natural e social.

A presente análise dá atenção a aspectos relacionados com a busca pela beleza e satisfação pessoal, experimentadas em fase de idade avançada. Os comportamentos das mulheres idosas, identificados com estes ideais, podem ser interpretados como reações à sensação de impotência, ansiedade e medo diante da finitude da vida. Estes aspectos, inclusive, podem ser explicados, ainda que parcialmente, pelas considerações dos autores clássicos acima referidos, a partir da amplitude teórico-conceitual do fenômeno do Mal-Estar na Civilização e na Pós-Modernidade. Outros autores, a exemplo de Silva (2005) e Bittencourt (2010), promovem novos olhares sobre 
essas obras clássicas e defendem a necessidade de outras formas de organização social.

Neste texto, as relações contemporâneas entre velhice, moda, mídia e consumo são abordadas a partir de Debert (2003, 2004), Clarke (2016), Lipovetsky (1989, 2007), Cidreira (2005), Palacios (2008), dentre outros autores. O contexto de interação social no qual as mulheres idosas encontram-se inseridas no documentário, demonstra como a indústria da moda e o campo midiático possibilitam a materialização de uma realidade marcada pelas relações de consumo e busca pelo bem-estar. Em uma mesma ambiência midiática, novas formas de interpretação e de vivência da velhice convivem com interpretações mais tradicionais e socialmente cristalizadas. Estas últimas, são reconhecidamente marcadas por interpretações de estados de solidão, de isolamento, de acometimento de doenças e de dependência, dentre outros aspectos associados a imagens depreciativas da velhice (PALACIOS, 2008).

Oportuno destacar que, quando se fala de velhice, neste texto, certos aspectos de ordem biossocial não são aprofundados, por se tratar de uma análise mais circunscrita aos processos de representação da velhice na ambiência midiática e especialmente retratados no documentário em foco. Este propósito justifica o fato de a velhice ser tratada no singular, em que pesem as evidências de que não se trata de uma fase da vida marcada pela homogeneidade. Sabe-se que, semelhantemente a outras faixas etárias, para as quais existem expressões convencionalmente aceitas que assinalam distinções internas, tais como "primeira infância" e "jovem adulto", na velhice, pode-se também dizer que há "velhos mais jovens" e "velhos mais velhos" (BRITTO DA MOTTA, 2010). 
Observa-se que o documentário Advanced Style, ao mesmo tempo que apresenta algumas angústias associadas à velhice, tais como, a fragilidade do corpo e a ameaça de demência, também põe em relevo, a autonomia, a elegância, a beleza e a criatividade de um grupo de mulheres idosas que entendem a moda não apenas como consumo, mas como a expressão de originalidade, de liberdade, de modo e estilo de vida próprios. Entretanto, cumpre-se fazer a ressalva que as senhoras do Advanced Style estão inseridas em um contexto social específico de prestígio social. Ainda assim, o documentário discute 0 crescimento de representações positivas da velhice, na mídia e na moda, diante do crescimento mundial do número de pessoas mais velhas e sua posição, enquanto atores políticos, na ampliação dos mercados de consumo.

\section{CULTURA, VELHICE E MAL-ESTAR PÓS-MODERNO}

A partir de uma compreensão de civilização e cultura enquanto sinônimos, Freud ([1930] 1996) em seu livro MalEstar na civilização examinou as razões do sofrimento do homem moderno e concluiu que a civilização impõe algumas exigências que não possibilitam o nosso projeto de felicidade. "O homem civilizado trocou uma parcela de suas possibilidades de felicidade por uma parcela de segurança". (Freud, [1930] 1996, p.73). As exigências de limpeza e de ordem, por exemplo, aparecem como requisitos da vida social que demandam escolhas e, por vezes, sacrifícios e insatisfações, ainda que possam ser sublimados. Segundo Freud ([1930]1996), tais exigências permanecem de forma inconsciente no indivíduo e, deste modo, as pessoas sempre estarão buscando outras motivações para conviver com tais sensações. "O preço que pagamos por nosso avanço em termos de civilização é uma perda de felicidade pela 
intensificação do sentimento de culpa" (Freud, [1930]1996, p.84).

O sentimento de culpa é apontado por Freud ([1930]1996) como o mais importante problema no desenvolvimento da civilização, no que diz respeito à necessidade de se viver coletivamente. De tal necessidade, conforme o autor, decorre a eterna luta entre as tendências de amor e de morte. Segundo Freud ([1930]1996), uma das razões para essa inquietação e sofrimento é a falta de controle sobre as forças da natureza e sobre a fragilidade do nosso corpo, que sensível a tudo que é exterior, traduz-se no organismo onde se torna possível sentir a finitude da vida. Sendo assim, o corpo também se transforma em fonte de infelicidade, contribuindo para a ansiedade e a sensação de inadequação do sujeito, em meio às regras impostas pela sociedade, pelo estado e pela família (FREUD, [1930]1996).

Buscando interpretar o pensamento de Freud, Marcuse ([1955]1975) critica a dinâmica opressora dos sujeitos, inseridos em um sistema social, político e econômico voltado para a lógica do mercado. Conforme este autor, o engajamento no regime produtivo gera ansiedade, sofrimento e mal-estar. Marcuse ([1955]1975), ao discordar de Freud, defende que é necessário lutar contra o Princípio de Realidade imposto por sociedades repressivas, para encontrar a felicidade e eliminar as condições castradoras de prazer e liberdade e abrir espaço para o lúdico, por meio do qual instintos de vida seriam libertados.

Silva (2005), retomando a obra de Marcuse, destaca o papel da fantasia e da arte como forças de oposição ao Princípio de Realidade, por manifestarem a possibilidade de que "a espécie venha a instituir novas maneiras de organização social, em cujo seio desapareça a repressão e o homem não seja mais o agressor, tanto de seu semelhante quanto da natureza" (Silva, 2005, p. 6). 
Esta problemática também está presente nas reflexões de Bauman (1998), quando estende e atualiza os fundamentos do referencial freudiano, no que convencionou chamar de o Mal-Estar na Pós-Modernidade. Uma das principais contribuições assinaladas por Bauman (1998) é a sugestão de que o fenômeno do Mal-Estar contemporâneo não representa uma etapa superior no tempo, mas sim, uma condição de novas incertezas e inquietações, ainda ligadas às transformações da modernidade.

Bauman (1998), inspirado nas elaborações de Freud ([1930]1996), assinala que valores, tais como, o desejo de controle e ordem de um mundo estável, seguro, limpo, coerente e puro, limitam a liberdade do indivíduo e da sociedade, em nome da segurança. Nesse sentido, mais ordem significa também, mais Mal-Estar e novas desordens. Paradoxalmente, segundo Bauman (1998), o Mal-Estar existe, atualmente, pelo excesso de liberdade e não de repressão.

Aproximando-se do fenômeno da centralidade do consumo na cultura contemporânea, Bauman (1998) destaca que o excesso de liberdade, pode ser verificado nas escolhas disponíveis de compra, em que o indivíduo cada vez mais se perde dentre tantas opções que prometem expressar traços de sua identidade e sensação de felicidade, e que logo são transferidas para a expectativa de uma nova compra. Nesse sentido, para Bauman (1998), existe um paradoxo entre o desejo de liberdade e de segurança: ao desfrutar de uma, ao mesmo tempo, perde-se um pouco da outra. E assim, o indivíduo, submetido a exigências e regras socialmente impostas, não encontra a felicidade que tanto deseja.

Bittencourt (2010), ao retomar os argumentos de Bauman (1998) sobre o Mal-Estar na Pós-Modernidade, nota que a violência está presente em todos os espaços na vida 
social pós-moderna, além do constante medo e perda da confiança na coletividade social. O autor afirma que o legado de Bauman, a partir de suas diversas obras, "apresenta a crueza da 'vida líquida', mas ao mesmo tempo, nos mune de uma via de superação da crise de valores que consome as qualidades da humanidade contemporânea" (Bittencourt, 2010, p. 84). O autor conclui, defendendo que:

Sua consistência argumentativa se manifesta justamente na possibilidade de analisarmos o rumo existencial que escolhemos seguir na dita pósmodernidade e a capacidade de desenvolvermos uma orientação de vida mais sólida e substanciosa, mediante a valorização das diferenças existenciais com as quais interagimos em nossa existência cotidiana (BITTENCOURT, 2010, p. 84).

De acordo com Bevilacqua e Macêdo (2012), as teorias centradas na psicologia, antropologia do consumo e economia que buscam clarificar as relações contidas no consumo, parecem convergir para o entendimento de que o consumidor, por meio da adoção ou execução de hábitos e práticas de consumo, realiza ou empreende uma busca pela felicidade. Com a hipótese de que a partir dos anos 1970 se estabeleceu uma nova fase do consumo (o Hiperconsumo) e de estruturação do capitalismo, Lipovetsky (2007) afirma que essa sociedade é a Civilização da felicidade paradoxal, que tende a confundir bem-estar material e vida feliz. Se por um lado, o consumidor é cada vez mais livre e informado, por outro, é cada vez mais dependente do sistema mercantil para ter acesso aos prazeres, fontes de satisfações e sensações de felicidade.

Entretanto, a imposição de que todos precisam colaborar com o ciclo consumista é apenas uma das cobranças presentes nos valores estimulados na pós-modernidade. Somam-se à esta exigência, o imperativo de que se deve parecer mais jovem e, principalmente, o desejo de se prolongar a vida. Este último, constitui um dos Mal-estares 
destacados por Bauman (1998). O autor ainda questiona quais seriam os prováveis significados e consequências culturais da imortalidade no contexto social no qual estamos vivenciando.

Harari (2016) também coloca como um dos projetos da nova agenda humana a superação da velhice e da morte, que é entendida como uma falha técnica, já que a maioria das pessoas morre de enfermidades não infecciosas, como o câncer e doenças cardiovasculares ou, simplesmente, de velhice. Contudo, o desafio maior para essa sociedade, que poderá vir a se constituir de seres amortais, residirá em como trazer a felicidade e o controle do corpo. "Ao buscar a felicidade e a imortalidade, os humanos estão na verdade tentando promover-se à condição de deuses" (Harari, 2016, p.47). Esta condição, antecipa o autor, gerará outros, e mais acentuados, tipos de ansiedade no lastro da história humana.

De acordo com Palacios (2008), o envelhecimento da população é uma tendência demográfica mundial, atestada por diversas instituições, institutos de pesquisa, organismos internacionais e órgãos governamentais. A tendência decorre do decréscimo da taxa de natalidade e do crescimento da média de vida das populações, a partir de avanços das ciências e tecnologias médicas. Nesse sentido, não é por acaso que os idosos têm ganhado mais importância também na definição de novos mercados de consumo, enquanto atores políticos dignos de direitos sociais.

A partir de novos comportamentos, conforme Debert (2004), a tendência contemporânea é rever os estereótipos associados ao envelhecimento e à associação da velhice com a ideia de que se traduz, exclusivamente, em um processo de perdas. Essa visão tem sido substituída pela consideração de que os estágios mais avançados da vida são momentos 
propícios para novas conquistas, guiados pela busca do prazer e da satisfação pessoal.

Atualmente, dentre os múltiplos qualificativos associados à velhice, como parte de um certo reconhecimento de que novas vivências e modos de estar no mundo vêm ocorrendo e que também decorrem do protagonismo que parcelas das populações idosas com poder de consumo vêm alcançando na ambiência midiática, destaca-se a designação 3T, que significa "Trocar o Tricô pelo Teclado". As pessoas idosas, conforme Ruppenthal e Schemes (2016, p. 319), "São pessoas maduras que já presenciaram mudanças radicais no mundo e, para elas, essa revolução tecnológica é só mais uma", à qual podem aderir sem maiores dificuldades.

Contudo, para melhor situar as relações entre a cultura, moda e a velhice, a partir do documentário que também é um produto midiático, é indispensável aproximar esta reflexão do contexto sócio cultural concreto no qual se inserem os sujeitos idosos. Especificamente, no caso do Brasil, tal contexto é marcado por profundas desigualdades sócio-econômicas, que têm efeitos nos processos de interação social, no acesso aos bens e serviços básicos (saúde, educação e moradia), como também nas relações de consumo. Portanto, é mister enfatizar que o documentário Advanced Style se refere a uma parcela de mulheres idosas bastante restrita e não à população idosa em sua totalidade.

A partir deste enquadramento, a presente reflexão postula pensar o corpo no processo de envelhecimento, além de procurar identificar e compreender quais outros valores estéticos e vivenciais são estimulados pela moda e pela mídia. Sabe-se, de antemão, que são valores que atualmente se organizam, hegemonicamente, em torno de um ideal de beleza e de saúde corporal associado à juventude.

\section{MODA, MÍDIA E ESTILO DE VIDA JOVEM}


A moda é um fenômeno que tem ocupado espaço significativo na cultura contemporânea. Unida às mídias, à indústria, e também à arte e ao entretenimento, vem estimulando comportamentos, busca por estilos, ideais de beleza e a constante exploração das imagens corporais. Já no princípio do século $X X$, o fenômeno social da moda suscitou reflexão de base filosófica e sociológica por parte de George Simmel (1858-1918), demonstrando, ao longo do tempo, sua importância nos processos de organização social.

Waizbort (2008, p. 8) destaca que, em Philosophie der Mode (1905), Simmel parte de uma antropologia fundante, nomeadamente da assunção de que o ser humano é um ser dualista. Waizbort (2008, p. 8) põe em relevo que o dualismo que perpassa a existência humana pode ser percebido menos em sua fundamentação última, inescrutável, do que justamente em suas formas fenomênicas e exteriores. E explica, a partir de Simmel, que:

Uma das formas fenomênicas desse dualismo revela-se, na "história da sociedade", na luta e nos ajustes entre as tendências sociais e individuais de fusão do indivíduo com o grupo e de elevação do indivíduo diante do grupo, ou seja, na luta pelas tendências particularisantes e universalisantes, diferença e identidade (WAIZBORT, 2008, p. 8).

A obra de Lipovetsky, especialmente O Império do Efêmero (1989), contribui para entender como se deu o desenvolvimento dessa dinâmica durante grande parte do século XX. O autor dá ênfase às correlações entre a moda e as transformações do mundo moderno ocidental, especialmente no âmbito do indivíduo e suas relações com as práticas de consumo e com a mídia. Lipovetsky (1989) sugere que a moda pode ser entendida como um sistema, que composto por um movimento circular, introduz a 
novidade como um valor na cultura ocidental. E assim, a moda incentiva uma dinâmica de mudança periódica de estilo, exaltação do gosto pela novidade, tendo a aparência um lugar de destaque, mas também presente em lógicas produtivas de outros setores sociais.

Lipovetsky (1989) explica que a partir de um determinado momento histórico de maior democratização dos produtos, no Prêt-à-porter, que se sobrepôs à lógica da Alta-costura, a moda começou, de forma mais determinante, a dar pleno relevo aos valores da estética jovem, ao invés de considerá-los apenas como códigos de distinção social de classe. "A Alta-costura, com sua grande tradição de refinamento distinto, com seus modelos destinados às mulheres adultas e 'instaladas', foi desqualificada por essa nova exigência do individualismo moderno: parecer jovem" (Lipovetsky, 1989, p. 121).

Partindo de uma noção complementar, Cidreira (2005) relaciona a moda também com a maneira de ser, de se comportar, modo de viver e de se vestir, na proximidade entre os termos moda e modo. "Oriunda do latim modus que significa maneira, a moda é denominada como maneira, modo individual de fazer, ou uso passageiro que regula a forma dos objetos materiais, e particularmente, os móveis, as vestimentas e a coqueteria (Cidreira, 2005, p. 30). A autora acrescenta, ainda, que a noção pode ser também um espaço de mediação entre indivíduos, além de expressão cultural, na medida em que a roupa partilha sentido, por se encontrar sempre junto ao corpo, como se fosse uma segunda pele.

A partir dos anos 1930 e 1940, Paris deixa de ser o único espaço referencial que dita a moda e ganham visibilidade os filmes de Hollywood. Segundo Matos (2015), inicia-se aí uma profusão de imagens de corpos veiculadas pelas passarelas e anúncios de moda, cinema, indústria 
fonográfica, revistas e pela publicidade, que contribuíram para um novo padrão de corpo saudável e belo. Padrão este que, referendado pelo discurso médico e pelo ideal de beleza vigente, em aliança com a busca pela Saúde perfeita (SFEZ, 1995), transforma-se em paradigma, à luz do qual o corpo envelhecido e os sinais da velhice nele impressos tendem a ser vistos como consequência do descuido pessoal. Instalase, conforme atesta Matos (2015, p.77), "A busca pela aparência sã. A medicina começa a sublinhar a importância de exercícios e vida saudável para preservar, não somente a saúde, mas também a frescura da tez, a pele saudável, 0 corpo firme e jovem".

Assim, a indústria da moda, imprensa, cinema e a publicidade influenciam toda uma relação expressiva de estilo de vida, beleza e bem-estar do indivíduo e, principalmente, das mulheres, orientando como deve ser o contato com o próprio corpo, em busca de uma aparência jovem. De acordo com Castro (2007), a preocupação com a apresentação do corpo vem assumindo centralidade na vida cotidiana, a ponto de os locais de culto ao corpo, a exemplo das academias, caracterizarem-se como espaços para se estabelecer formas de sociabilidade, construir marcas identitárias e de distinção social. Cenário que contribui para inscrever o corpo, cada vez mais, como território de construção e expressão de identidade na cultura contemporânea.

Junto ao desejo de um físico belo, adequado ao apelo ou imperativo da juventude, ocorre uma crescente manipulação do corpo, busca pela perfeição, ansiedade e a negação da velhice. De acordo com Debert (2004, p.21), a juventude perde conexão com um grupo etário específico e estágio de vida para se transformar em um valor, um bem a ser conquistado em qualquer idade. Ou seja, estilo de vida e práticas de consumo associados aos ideais de felicidade, 
sucesso, autonomia e beleza são difíceis de serem alcançados e têm levado, inclusive, as pessoas a sofrerem ainda mais.

São criadas opções de bem-estar que também são opções de consumo em uma crescente apropriação do corpo pela ciência. Nesse contexto, as intervenções transformadoras do corpo, com o objetivo de parecer jovem, de acordo com Villaça (2010), decorrem de uma nova dinâmica biopsicosociológica surgida no horizonte das novas tecnologias, que oferece ao sujeito a possibilidade da aceitação ou recusa do corpo. Entretanto, é preciso atentar ainda, segundo Villaça (2010), para o fato de que a economia, com sua lógica de suscitar e satisfazer necessidades, exclui as pessoas idosas que não dispõem de renda para serem cidadãos e consumidores. Prodanov e Reinke (2016, p. 122) chamam atenção para as relações entre a velhice e os aspectos do consumo e observam:

[...] que essa parcela da população era, até pouco tempo, marginalizada por ser percebida como socialmente incapaz de influenciar a atitude dos outros indivíduos, ou seja, não seria lançadora de tendência, também por não representar um poder de compra considerável a ponto de se investir nesse público (PRODANOV e REINKE, 2016, p. 122).

Até os anos 1970, a literatura publicada na Inglaterra e na América do Norte, segundo Debert (2003), indica que maioria das imagens dos idosos na mídia era negativa e desrespeitosa e acentuava os estados de dependência e de isolamento. Ainda segundo a autora, a partir dos anos 80 , a pessoa idosa passou a ser representada de maneira mais positiva, passando a simbolizar o poder, a riqueza, a perspicácia e prestígio social. Mesmo assim, em maior parte, a pessoa idosa é representada por homens, enquanto as 
mulheres são relegadas a papeis secundários. Clarke (2016) afirma que, de um modo geral, esta tendência ainda permanece, na América do Norte. Contudo, embora sejam considerados invisíveis na ambiência midiática os adultos masculinos mais velhos têm sido representados de formas mais positivas, enquanto as mulheres mais velhas, ainda são sub representadas, comparativamente aos homens.

\section{MODA E VELHICE NO DOCUMENTÁRIO ADVANCED STYLE}

A escolha do Advanced Style é oportuna como caso ilustrativo da existência de tendências contrárias ao padrão estético vigente, por promover a valorização de sete mulheres idosas, com destaque para aspectos de suas vidas ativas e orientadas pela criatividade. A notoriedade alcançada pelo documentário, pelo blog ${ }^{1}$ e pelo livro de mesmo nome, reforça a propriedade de sua escolha. Os três produtos contribuem para o debate existente no campo da moda, sobre o envelhecimento e padrões de beleza. Produzido por meio de uma campanha de financiamento coletivo na internet ${ }^{2}$, o documentário foi lançado nos Estados Unidos, em 2014, e disponibilizado na plataforma online Netflix, entre 2015 e 2017. Já o livro foi lançado em 2012 e cenas do seu lançamento também são exibidas no documentário.

Ao título do filme em português, disponível no site, foi acrescentada a expressão Vovós Fashion. Vale chamar a atenção que o universo simbólico evocado por esta expressão parece pressupor que as mulheres ao chegarem à velhice tenham, necessariamente, que desempenhar o papel de avós, mesmo a despeito da real possibilidade de uma

\footnotetext{
${ }_{1}^{1}$ Disponível em: <http://www.advanced.style>. Acesso em: 10/03/2018.

2 Disponível em: <https://www.kickstarter.com/projects/292182391/advanced-style-film> Acesso em $15 / 02 / 2018$.
} 
mulher, na vida adulta, optar por não ter tido filhos. O documentário contraria este traço identitário evocado pela expressão acrescentada em português, no Brasil. O substantivo vovós, mesmo acompanhado pelo adjetivo fashion, pode vir a reforçar um conhecido pressuposto inserido no imaginário social, por meio do qual "ser uma mulher idosa significa ser, principalmente, avó". Este acréscimo confronta 0 fato de que as mulheres idosas destacadas no documentário são criativas, autônomas, solteiras, casadas, viúvas, engajadas socialmente e possuem visibilidade midiática por desempenharem papeis que vão além do papel de vovós.

Em síntese, o subtítulo acrescido ao título original, em língua portuguesa, vem corroborar a solidez de uma representação social majoritária e cristalizada no imaginário social sobre as mulheres idosas, no Brasil. Este acréscimo reflete o quão dominante é, no país, a visão reacionária sobre os papeis sociais desempenhados pela mulher, mesmo em pleno século XXI. Reforça o fato paradoxal de 0 qualificativo empregado (Vovós Fashion) ter sido aposto a uma peça midiática que se contrapõe a este padrão.

Acerca dos papeis sociais desempenhados pelas mulheres na sociedade brasileira, Schemes, Montardo e Prodanov (2017, p. 94) mencionam uma observação de Goldenberg (2008) por meio da qual a antropóloga compara os processos de emancipação da mulher europeia, especialmente as alemãs, aos da mulher brasileira, especialmente, as cariocas:

A liberdade das brasileiras parece ser uma conquista tardia que se dá após cumprirem papéis obrigatórios de esposa e mãe. Suas necessidades pessoais ficam sendo secundárias, fazendo, assim, com que seja difícil retomar sua vida após a família não precisar mais de seu apoio (GOLDENBERG, 2008, apud SCHEMES, MONTARDO e PRODANOV, 2017, p. 94). 
Schemes, Montardo e Prodanov (2017, p. 90) realizam uma análise do blog Advanced Style com o objetivo de entender como "é apresentada uma performance de envelhecimento associada à moda". O blog deu origem ao documentário e ao livro, e é parte do fenômeno contemporâneo dos blogs de moda na internet, que tem contribuído para criar outras narrativas sobre a moda, para além da mídia especializada. Foi fundado em 2008 pelo fotógrafo Ari Seth Cohen, que anda pelas ruas de Nova York à procura de mulheres idosas da cidade que demonstrem beleza, elegância e estilo próprio. De acordo com Cidreira (2005), ter estilo próprio pode ser interpretado como um conjunto de traços identitários que resultam em uma unicidade. Condição que auxilia a reconhecer também, segundo a pesquisadora, "o consumidor participante do jogo da moda capaz de se apropriar de modo singular de uma, duas peças do vestuário, numa atitude criativa, que consegue, assim, ser ao mesmo tempo universal e particular" (Cidreira, 2005, p. 127).

"O ato de vestir pode ter efeitos físicos e emocionais nas mulheres jovens e velhas" assinalam Schemes, Duarte e Magalhães (2015, p. 51). Conforme os autores, para as mulheres mais velhas, este ato "pode signifcar um momento de desprendimento, de liberdade, de criatividade, já que nesse momento da vida não há mais tantas preocupações profissionais, sociais, com os filhos, etc." (2015, p. 151). Contudo, acrescentam que o início do envelhecimento pode trazer algumas limitações quanto à escolha do que vestir: "Há quem não perceba tais mudanças em si mesmo, porém, mesmo que sutis, a vida da mulher que passa dos sessenta anos muda em vários aspectos, e um deles pode ser seu modo de vestir, que pode influenciar a própria identidade feminina" (Schemes, Duarte e Magalhães 2015, p 151). 
Cohen (2014) defende que as mulheres maduras mudam a concepção sobre envelhecimento a partir de uma atitude ativa e criativa da vida. "Nova York é a cidade para as madames do Advanced Style porque elas podem usar amplas avenidas e ruas como passarelas", disse ele, que também participa do documentário como roteirista. Cohen (2014) acrescenta que criou o projeto como uma maneira de homenagear e estar próximo a suas avós, sem imaginar que o blog acabaria se tornando um movimento, mudando a vida delas e inspirando a indústria da moda.

Logo no início do documentário, uma das fontes é Iris Apfel, reconhecida personalidade midiática que dá voz a esse novo olhar sobre a moda e a velhice. Aos 96 anos, Apfel é empresária, designer de interiores e ícone da moda norteamericana. Sua postura fomenta o debate crítico sobre os padrões de beleza jovens impostos pela indústria cultural e da moda. Segundo ela, tais padrões orientam-se pela representação feminina nas imagens de moda que utilizam modelos muito jovens, bem produzidas, com muitos retoques e maquiagem. $\mathrm{O}$ padrão estético gerado por estas imagens cria exigências que Apfel acredita serem impossíveis de seguir.

As sete personagens destacadas no filme possuem de 62 a 96 anos, algumas são solteiras, sem filhos, sendo uma delas viúva e outra casada pela segunda vez. Em relação à profissão, a maioria está ligada a atividades criativas ou artísticas, como pintura, dança, canto ou moda, a exemplo de Lynn Dell, de 79 anos, dona da Off Broadway, uma boutique de Nova York que aparece nas filmagens. Outra personagem destacada é Joyce Carpati, de 80 anos, aposentada e com uma trajetória de vida que inclui a atuação em revistas de moda, como a Cosmopolitan e a Good Housekeeping. Além disso, Carpati ainda se dedica à música, como cantora de ópera. 
Todas são mulheres que andam maquiadas, utilizam muitos adereços e assessórios, como chapéus, colares e pulseiras, roupas muito coloridas com texturas, estampas e várias sobreposições, demonstrando um estilo lúdico ou até mesmo exótico. Todas elas expressam que essa produção, na composição da sua aparência, reflete uma predileção pessoal, afetiva, criativa e, até mesmo, de alguma forma, artística. Elas atuam como estilistas de si mesmas e consideram o próprio corpo como um suporte para criação.

Figura 1: Imagem de divulgação do documentário Advanced Style.

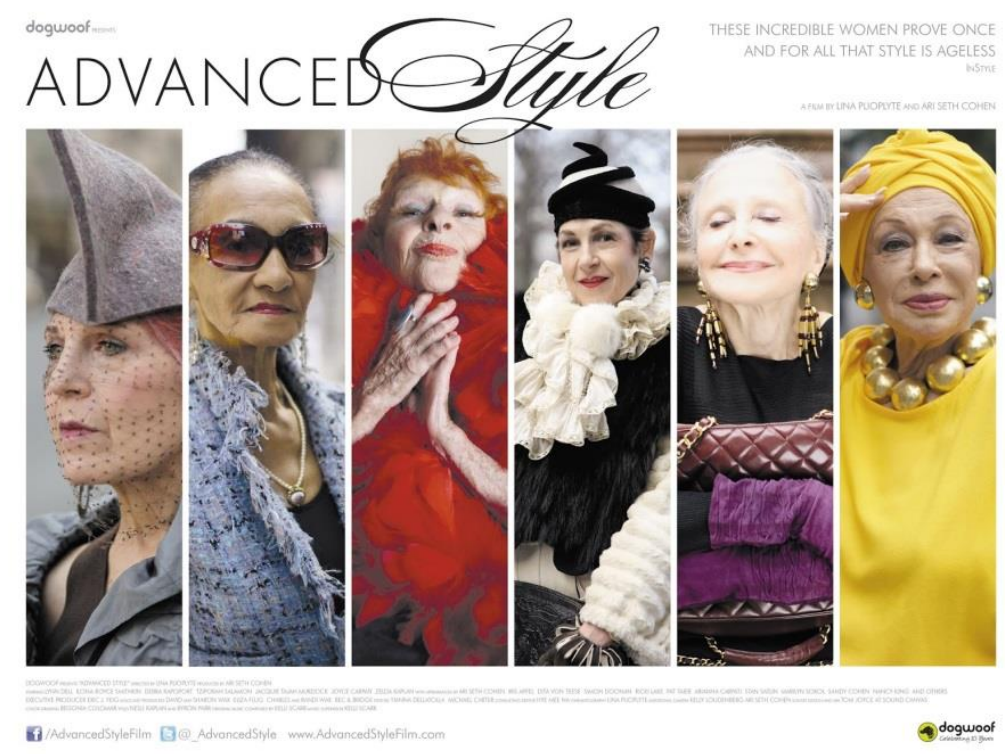

Fonte: https://ffw.uol.com.br/lifestyle/cultura/blogadvanced-style-vira-documentario-e-voce-pode-assistirpelo-netflix-785/. Acesso em: 07 set 2018.

Ilona Smithkin, 93 anos, fabricou seus cílios postiços com o próprio cabelo ruivo. Zelda Kaplan, 95 anos, diz que desenha e costura suas roupas. Tziporah Salamon, 62 anos, afirma, em uma das cenas, que cuida de suas bolsas, sapatos, chapéus e jaquetas de algum modo como dos filhos que não teve, pois precisam de constante cuidado. Debrah Rapoport, 67 anos, conta como seu companheiro estranhava seu estilo quando a conheceu. Para ela, a moda tem a ver 
com tendências, sobre o que é novo e o que vende. É diferente do estilo, que não se compra com dinheiro. Esta questão é tema da campanha publicitária que protagonizou. Ela também gosta de caminhar pela cidade e de praticar ioga.

Jacquie Murdock, 81 anos, antiga dançarina de um influente teatro da cidade, também estampou campanha da marca francesa Lanvin. Os bastidores do ensaio fotográfico são apresentados no documentário. Ela se mostra realizada, já que sempre amou a moda, sente-se estilosa e acompanha as revistas do segmento. Tziporah Salamon, 62 anos, também participou da campanha e é a mais jovem de todas. Ela diz que anda de bicicleta para mostrar suas roupas e que não se sente com a idade que tem. Relata também dificuldades de conseguir um trabalho como anfitriã de restaurante pela sua idade e por seu estilo, que assusta as pessoas por ser considerado exótico demais.

Figura 2: Imagem de divulgação do documentário Advanced Style.

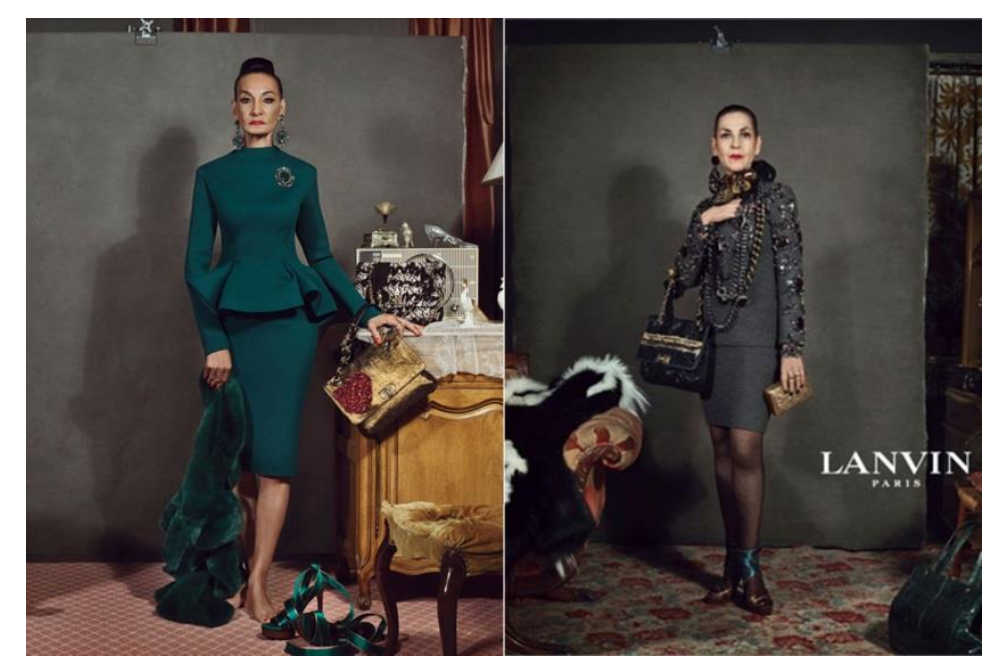

Fonte: https://ffw.uol.com.br/lifestyle/cultura/blogadvanced-style-vira-documentario-e-voce-podeassistir-pelo-netflix-785/. Acesso em: 07 set. 2018)

Inclusive, a excentricidade é um dos aspectos destacados no blog de mesmo nome e mencionado por Schemes, Montardo e Prodanov (2017, p. 99): 
O excêntrico está relacionado àquilo que foge do comum e, na moda, se refere ao exagero, à autenticidade, ao novo, à mistura de referências, cores e texturas. No Advanced Style, esse estilo sobressai em relação aos outros, apresentando idosas que se diferenciam com seus acessórios modernos e de tamanho maxi, muitas estampas coloridas, cores vibrantes, cabelos de cores e cortes ousados e sobreposição de roupas. (SCHEMES, MONTARDO e PRODANOV, 2017, p. 99).

Já o documentário expõe o modo como cada uma quer lidar com sua velhice. Lynn Dell, 79 anos, diz querer aproveitar a vida, viajar e ser mais feliz; demonstra preocupação com a sensação de que o fim da vida está perto e com os cuidados de saúde do marido, que já não enxerga bem. Já Ilona Royce Smithkin, 93 anos, mostra-se satisfeita com tudo que já fez no passado, que está feliz, contente e realizada com quem é agora, não sente essa urgência e não quer mais provar nada para ninguém. Para Zelda Kaplan, 95 anos, envelhecer ensina-a a aceitar que não consegue mais dançar como antes.

De modo geral, o filme mostra como essas mulheres vivem bem e aceitam a velhice com prazer, tendo a aparência e o estilo como manifestações de tal bem-estar. 0 filme, além de evidenciar as sensações de liberdade e felicidade por elas expressadas, também retrata como lidam com as sensações de angústia, inseguranças e problemas de saúde relacionados a essa etapa da vida. A convivência e relação de cumplicidade com os companheiros, como é o caso de Debrah Rapoport, 67 anos, é também enfocada.

Outras contam como tentam lidar com o fato de não ter casado ou não ter tido filhos. Jacquie Murdock, por exemplo, lamenta não ter encontrado um marido, mas alega que, aos 81 anos, gostaria ainda de se casar com alguém que gostasse de sair para jantar e ir a eventos culturais. Tziporah Salamon, 62 anos, também conta sua expectativa 
de se casar com alguém que tenha filhos, para assim realizar a sua vontade de ser mãe, o que não aconteceu antes, pois não queria ser uma mãe solteira.

Joyce Carpati, 80 anos, conta como lidou com a morte do marido ainda muito jovem, tendo que se dedicar ao trabalho. Ela é a única com filhos e netos. Sua neta se mostra orgulhosa da avó pelas coisas que fez na vida, além do estilo que cultiva. As duas aparecem em uma das cenas, experimentando acessórios e conversando sobre moda. Carpati diz que ela irá herdar suas roupas e lhe dá uma bolsa de presente. O documentário ainda revela a vontade de desfrutar da vida, como é o caso de Ilona Smithkin, 93 anos, enquanto marido e amigas de mais idade estão vivos. Smithkin aparece visitando uma amiga mais velha que perdeu a memória.

Em determinado momento, a narrativa exibe uma sequência com algumas delas falando mais diretamente sobre saúde e expectativa da morte, como Lynn Dell, 79 anos, que chegou a ser filmada internada em um hospital por seis semanas, devido a complicações no apêndice. Elas falam sobre os remédios, as dores no corpo e sobre os problemas de saúde com os quais têm que lidar. Falam também sobre o receio do ambiente dos hospitais; sensações e preocupações que, segundo elas, inexistem durante a juventude.

Em sequência, o documentário exibe um desfile com várias mulheres idosas promovido na área externa de onde ocorria o New York Fashion Week, importante evento de moda do país e um dos principais do calendário da moda em todo o mundo. O evento acabou sendo o cenário de um desfecho dramático. O som de sirene de uma ambulância, imagens de velório e de notícias de jornais e sites anunciavam a morte de Zelda Kaplan, 95 anos, que estava assistindo ao desfile na primeira fila, quando passou mal e 
foi levada ao hospital, vindo, em seguida, a falecer, vítima de um infarto.

A partir deste fato, as outras protagonistas parecem não acreditar no que aconteceu e lamentam a perda, mas chamando a atenção de que ela morreu após um momento feliz. Assim, o filme termina exibindo imagens de todas elas sorrindo, cantando, participando de festas. Em meio a esse clima, o filme parece deixar a mensagem de que a morte é sempre uma iminente fatalidade, a qualquer idade. Diante da imponderável finitude da vida, deve-se viver o presente, buscar a felicidade e o prazer de vivê-la.

\section{CONSIDERAÇÕES FINAIS}

O documentário demonstra a notoriedade que o blog alcançou e como ajudou a chamar atenção para a condição da velhice, ao questionar padrões de beleza e expor a transformação na vida dessas mulheres, a partir de suas participações em eventos de moda, na mídia e em campanhas publicitárias de grandes marcas da indústria da moda. De forma geral, estes fatos corroboram uma vertente atual, no debate sobre os papéis sociais desempenhados na velhice, que aponta para a crescente, embora ainda diminuta, presença da mulher idosa, no cenário midiático (CLARKE, 2016). De uma forma específica, fortalecem uma tendência, dentro do sistema da moda, de que há um crescimento de representações positivas da velhice, nas atuais imagens deste segmento. Nessa direção, algumas marcas e revistas têm adicionado pessoas idosas aos seus desfiles e em materiais de divulgação.

O mesmo fenômeno parece ocorrer no contexto produtivo da publicidade brasileira. Barbosa e Palacios (2016) demonstram como esta tendência acompanha o contexto social, ao fazerem referência ao aumento da 
presença dos idosos, na publicidade. Conforme as autoras, este fato está relacionado ao envelhecimento da população e ao objetivo da comunicação publicitária de alcançar segmentos de públicos idosos com (maior) poder aquisitivo. Acompanhando uma tendência mundial, nos Estados Unidos, país onde foi produzido o documentário, o envelhecimento da população também apresenta crescimento. Em 2010, a população, com idade acima de 65 anos, no país, alcançou um total de 40,3 milhões em apenas uma década, enquanto que, em 2000, o número de pessoas com mais 65 era de 35 milhões, registrando-se, portanto, um percentual de aumento de $15,1 \%$. 3

O documentário reforça a existência do processo de reinvenção da velhice apontado por Debert (2004), como um fenômeno social que envolve a reprivatização e a ressocialização da população idosa, sua posição enquanto ator político e a ampliação dos mercados de consumo. Embora o mundo representado pelas práticas de consumo possa ser interpretado como propulsor de prazeres efêmeros, as personagens do Advanced Style parecem não se importar tanto com o apelo ao consumo de tendências. A moda, para elas, se traduz em uma questão de expressão de um estilo, de um modo de vida próprio, de liberdade, criatividade e originalidade.

É importante também destacar que as senhoras do Advanced Style estão inseridas em um contexto social específico, no qual se destacam a experiência do envelhecimento associada ao gênero, à classe social, à disponibilidade de renda e à etnicidade. São mulheres que tiveram acesso à educação, possuem ou já possuíram uma profissão, além de terem à disposição serviços de saúde e acesso a bens de consumo. Aparecem também frequentando locais nobres da cidade de Nova York, são bem posicionadas

${ }^{3}$ Informações disponíveis em: https://goo.gl/DvFBqf Acesso em 10/03/2018 
socialmente e com visibilidade no ambiente midiático. Nesse sentido, é forçoso ressaltar, ainda, que a situação social delas é diferente da maioria das mulheres mundo afora e, principalmente, das brasileiras, que se encontram na faixa etária destacada no documentário.

O prestigio social das mulheres retratadas no documentário, inclusive, pode estar relacionado às suas profissões e atividades que, ligadas à criatividade e ao campo artístico, dão mais espaço para o exercício da liberdade. Além disso, tal como aponta a antropóloga Miriam Goldenberg (2014), as pessoas que trabalham com criatividade, como intelectuais, artistas e escritores, parecem seres sem idade ou que não envelhecem. Conforme Clarke (2016), ageless é alguém sem idade definida.

Outros papéis sociais apresentados no documentário são aqueles relacionados ao universo social, histórica e culturalmente associado ao feminino, como o de mulher casada e de mãe. Há passagens no filme que tocam neste assunto e demonstram a existência de uma certa angústia em algumas personagens, ao relatarem que não tiveram filhos ou não se casaram. Entretanto, mostra a expectativa de duas delas que, apesar da idade, almejam ainda realizálos. Há também o papel de avó, que é apenas associado a Joyce Carpati, 80 anos, e não chega a ser algo diretamente explorado, demonstrando que essas mulheres possuem muitas outras possibilidades de experiências para viver na velhice, para além de serem avós.

Goldenberg (2014), reportando-se à obra $A$ velhice de Simone de Beauvoir, denuncia a conspiração do silencio em relação aos velhos e aponta que uma espécie de saída para viver uma Bela velhice seriam os projetos de vida, por possibilitarem a descoberta ou até o recomeço de antigos sonhos. Assim, as sete mulheres, personagens do documentário, parecem querer viver esta etapa da vida. São 
claras as referências pela busca de felicidade, liberdade e por uma vida ativa. Ao mesmo tempo em que também são claras as rejeições a certas maneiras de se viver a velhice como etapa da vida ligada a significados negativos, pejorativos, e a estereótipos e sensações de invisibilidade.

O que chama a atenção no documentário Advanced Style é o fato de a visibilidade alcançada por estas mulheres concorrer para a divulgação de modos e estilos de vida considerados inovadores frente às formas tradicionais de se conceber a vida, na velhice. Sua divulgação pode ainda vir a concorrer para mostrar a outras mulheres idosas, a possibilidade de se viver a velhice de outras formas. Neste caso específico, o documentário tem o objetivo de inspirar outras mulheres mais velhas, como as personagens, a buscar um estilo próprio de expressão, trazendo mais autoestima, feminilidade, sensações de prazer e de liberdade. Exemplo disso é a leitora do blog que foi até a boutique de Lynn Dell, 79 anos, e foi entrevistada. Ela afirmou que o blog mudou a sua vida e sua relação com o modo de se vestir, com muito mais criatividade.

Se, por um lado, o documentário mostra o lado belo da velhice, como um espaço de expressão livre do ser, também mostra alguns aspectos incômodos ligados ao envelhecimento. Sensações que envolvem insegurança, incertezas, ansiedades, medos, o desejo do controle e da ordem representam o lado sombrio da velhice. São os "problemas" da velhice que a cultura capitalista neoliberal sugere que podem ser atenuados com o consumo, como forma de promover o Bem-estar. Porém, como aponta o psicanalista Christian Dunker (2016), a negação do MalEstar como uma resposta ao sofrimento do modo de vida contemporâneo, não é o Bem-Estar e, sim, o Estar, pois a saída para sofrer menos pode ser amenizada por meio da 
adoção de uma identidade bem resolvida, construída a partir de diferentes experiências de felicidade.

O documentário também oferece poucas pistas para verificar as relações familiares das personagens, ficando a dúvida se são pessoas que vivem sozinhas e/ou cercadas do apoio de familiares e de pessoas amigas. Embora valorize a prática de exercícios e atividades ao ar livre nessa fase da vida, não deixa claro se recorrem a procedimentos de estética, se buscam retardar o envelhecimento do corpo e como elas lidam, individualmente, com as questões que envolvem a superação da velhice. Apenas Debra Rapoport, 67 anos, diz praticar ioga para manter o bem-estar e com o objetivo de ajudá-la a viver mais.

Contrariamente às imagens ainda dominantes na ambiência midiática e marcadas pela exposição da velhice como uma fase caracterizada pela perda de habilidades físicas, mentais e cognitivas, o documentário ressalta a beleza, o prestígio e a criatividade dessas mulheres, como fatores que concorrem para sua inserção social. Assim, o protagonismo das idosas em Advanced Style vem corroborar o pressuposto sócio cultural de que, às mulheres, os cuidados com a aparência são indispensáveis e cobrados de maneira muito mais exigente do que aos homens.

Advanced Style representa a velhice como uma fase de sabedoria e de inspiração para os mais jovens, enquanto ressalta que moda e estilo são maneiras de expressar a busca pela felicidade e pela liberdade de poder atribuir novos sentidos para a própria existência, em harmonia com a estética. No documentário, a velhice é uma etapa da vida na qual também se convive com a nostalgia do passado, com a melancolia do presente, frente à angústia proveniente da iniludível certeza da proximidade da morte ou do abandono da vida. Muito velada em nossa cultura e difícil de ser encarada, a morte é da ordem do inevitável; muito 
valorizada na nossa cultura, a imortalidade é uma possibilidade e um grande anseio humano.

\section{REFERÊNCIAS}

Advanced Style, 2014. Documentário. Direção Lina Plioplyte. Roteiro: Lina Plioplyte e Ari Seth Coehn. 112 minutos. Elenco: Joyce Carpati, Ari Cohen, Lynn Dell, Zelda Kaplan, Jacquie Murdock, Debra Rapoport, Tziporah Salamon e Ilona Smithkin. Disponível em:

https://www.netflix.com/title/80011082. Acesso em: 26 fev. 2018.

BAUMAN, Zigmunt. O Mal-Estar da Pós-Modernidade. Rio de Janeiro: Jorge Zahar, 1998.

BARBOSA, Denise dos Santos; PALACIOS, Annamaria da Rocha Jatobá. O Bordão "Folgado": a idosa em comerciais humorísticos da Renaut Duster. Anais do Congresso Nacional de Envelhecimento Humano. Natal, 2016. Disponível em: http://www.editorarealize.com.br/revistas/cneh/trabalhos/T RABALHO_EV054_MD2_SA12_ID1388_03102016205341.pdf . Acesso em: 26 fev. 2018.

BEVILACQUA, Solon. MACÊDO, Kátia Barbosa. Aspectos Culturais, Intrapsíquicos e Econômicos para o Consumo na Pós Modernidade. Anais Comunicon, São Paulo, 2012. Disponível em:

http://www.espm.br/download/Anais_Comunicon_2012/com unicon/gts/gtdez/Solon_katia.pdf. Acesso em: 26 fev. 2018.

BITTENCOURT, Renato Nunes. A Estrutura Simbólica da Vida Líquida em Zygmunt Bauman. In: Argumentos Revista de Filosofia. Ano 2, 4 ed, 2010. Disponível em: http://www.famesc.edu.br/famesc/biblioteca/livros_bauman /12.pdf. Acesso em: 26 fev. 2018.

BRITTO DA MOTTA, Alda. A Atualidade do Conceito de Gerações na Pesquisa Sobre o Envelhecimento. Soc. estado. vol.25 no.2 Brasília May/Aug. 2010. Disponível em: http://www.scielo.br/scielo.php?script=sci_arttext\&pid=S01 02-69922010000200005. Acesso em: 07 mar. 2018

CASTRO, Ana Lúcia de. Culto ao Corpo e Sociedade: mídia, estilos de vida e cultura de consumo. São Paulo: Annablume, 2007. 
CIDREIRA, Renata Pitombo. Os Sentidos da Moda. São Paulo: Annablume, 2005.

CLARKE, Laura Hurde. Envelhecimento, Idadismo e Invisibilidade dos Idosos na Mídia. Entrevista concedida a Maria Collier de Mendonça e Gisela G. S. Castro. In: Revista CMC Comunicação, Mídia e Consumo. São Paulo, v.13, n. 38, p. 151-155, set-dez, 2016. Disponível em: http://revistacmc.espm.br/index.php/revistacmc/issue/view/ 48/showToc. Acesso em: 12 mar. 2018.

COHEN, Ari Seth. In: Advanced Style, 2014. Direção Lina Plioplyte. Roteiro: Lina Plioplyte e Ari Seth Coehn. 112 minutos. Elenco: Joyce Carpati, Ari Cohen, Lynn Dell, Zelda Kaplan, Jacquie Murdock, Debra Rapoport, Tziporah Salamon e Ilona Smithkin. Disponível em:

https://www.netflix.com/title/80011082. Acesso em: 26 fev. 2018.

COHEN, Ari Seth. Advanced Style: Older \& Wiser. New York: PowerHouse Books, 2014.

DEBERT, Guita Grin. A Reinvenção da Velhice: socialização e processos de reprivatização do envelhecimento. São Paulo: Edusp, 2004.

DEBERT, Guita Grin. O velho na Propaganda. In: Cadernos Pagu, Campinas, n. 21, p. 133-155, 2003. Disponível em:

http://www.scielo.br/pdf/cpa/n21/n21a07.pdf. Acesso em: 15 fev. 2018.

DUNKER, Christian. Mal-estar, Sofrimento e Sintoma Programa Café Filosófico (ver. TV Cultura). Youtube, 04 jul. 2016. Disponível em:

https://www.youtube.com/watch?v=GV-75hpCdJY. Acesso em: 15 jan. 2018.

GIL, Antônio Carlos. Métodos e Técnicas de Pesquisa Social. 4 ed. São Paulo: Atlas, 1994.

Goldenberg, Mirian. A Bela Velhice - Programa Café Filosófico. Vimeo, 5 ago. 2014. Disponível em: https://vimeo.com/102667295. Acesso em: 15 jan. 2018. HARARI, Yuval Noah. Homo Deus: Uma breve história do amanhã. São Paulo: Companhia das letras, 2016.

FREUD, Sigmund. O Futuro de uma Ilusão, o Mal-estar na Civilização e Outros Trabalhos (1927-1931). Obras completas de Sigmund Freud. v. 21, Rio de Janeiro: Imago, 1996. 
LIPOVETSKY, Gilles. O Império do Efêmero: a moda e seu destino nas sociedades modernas. Trad. Maria Lucia Machado. São Paulo: Companhia das Letras, 1989.

LIPOVETSKY, Gilles. A felicidade paradoxal: ensaio sobre a sociedade de hiperconsumo. Trad. Maria Lucia Machado. São Paulo: Companhia das Letras, 2007.

MARCUSE, Herbert. Eros e Civilização: uma interpretação filosófica do pensamento de Freud [1955]. Rio de Janeiro: Zahar Editores, 1975.

MATOS, Cássio Luiz Aragão. A (Re)invenção do Corpo das Mulheres Idosas: imagens corporais na cultura contemporânea. Dissertação de mestrado. Programa Multidisciplinar de Pós-graduação em Cultura e Sociedade, Universidade Federal da Bahia, 2015. Disponível em: https://repositorio.ufba.br/ri/bitstream/ri/18434/1/A\%20REI NVEN\%C3\%87\%C3\%830\%20DO\%20CORPO\%20DA\%20MU LHER\%20IDOSA.pdf. Acesso em: 15 jan. 2018.

PALACIOS, Annamaria da Rocha Jatobá. Fragmentos do discurso publicitário no Brasil: novos velhos ou novos mercados de consumo? In: BOCC, 2008. Disponível em: http://www.bocc.ubi.pt/pag/palacios-annamariafragmentos-do-discurso-publicitario.pdf. Acesso em: 10 mar. 2018.

PRODANOV, Laura Schemes; REINKE, Carlos. A Mulher Madura e o Consumo de Moda no Brasil. Revista Prâksis. Novo Hamburgo, Rio Grande do Sul, a. 13, v. 1, p. 121-137. 2016. Disponível em:

http://periodicos.feevale.br/seer/index.php/revistapraksis/ar ticle/view/439/374. Acesso em: 10 mar. 2018.

RUPPENTHAL, Maiara; SCHEMES, Cláudia. Envelhecimento Ativo: mulheres maduras e suas percepções sobre a moda. ModaPalavra. E-periódico. Vv. 9, n. 17, 2016. Disponível em:

http://www.periodicos.udesc.br/index.php/modapalavra/arti cle/view/6567. Acesso em: 10 mar. 2018.

SCHEMES, Cláudia; Paulo H. Saul DUARTE; MAGALHÃES, Magna Lima. Anseios e Desejos: Mulher madura e a moda como construção social. Revista Prâksis. Novo Hamburgo/Rio Grande do Sul, a. 12, v. 2, ago. 2015. Disponível em:

http://periodicos.feevale.br/seer/index.php/revistapraksis/ar ticle/view/401/1627. Acesso em: 10 mar. 2018.

SCHEMES, Cláudia; MONTARDO, Sandra Portella; PRODANOV, Laura Schemes. "Celebre Cada Dia e Não Olhe para o Calendário": a representação do envelhecimento no Blog ADVANCED STYLE. Revista 
Conexão, V 16, no 31, Jan-Jun 2017. Disponível em: http://www.ucs.br/etc/revistas/index.php/conexao/article/vi ew/4805. Acesso em: 09 mar. 2018

SFEZ, Lucien. A Saúde Perfeita: crítica de uma nova utopia. São Paulo: Loyola, 1995.

SILVA, Rafael Cordeiro da. Arte e Reconciliação em Herbert Marcuse. In: Revista Trans/Form/Ação, vol. 28, no.1, Marília: 2005. Disponível em: http://www.scielo.br/scielo.php?script=sci_arttext\&pid=S01 01-31732005000100002. Acesso em: 15 fev. 2018.

VILLAÇA, Nízia. O corpo Periférico da Velhice. In: Mixologias: Comunicação e consumo da cultura. São Paulo: Estação das Letras e Cores, 2010.

WAIZBORT, Leopoldo. Georg Simmel Sobre a Moda uma aula. IARA - Revista de Moda, Cultura e Arte - São Paulo - v.1 n. 1 abr./ago. 2008. Disponível em: http://www1.sp.senac.br/hotsites/blogs/revistaiara/wpcontent/uploads/2015/01/03_IARA_Simmel_versaofinal.pdf. Acesso em: 10 fev. 2018 